American Journal of Infectious Diseases 2 (2): 58-66, 2006

ISSN 1553-6203

(C) 2006 Science Publications

\title{
Opiates Upregulate Adhesion Molecule Expression in Brain MicroVascular Endothelial Cells (BMVEC): Implications for Altered Blood Brain Barrier (BBB) Permeability
}

\author{
Madhavan P.N. Nair, Supriya D. Mahajan and Jessica L. Reynolds \\ Department of Medicine, Division of Allergy, Immunology and Rheumatology \\ State University of New York and Buffalo General Hospital, Kaleida Health \\ 100 High Street, Buffalo, NY 14203
}

\begin{abstract}
The blood-brain barrier (BBB) is an intricate cellular system composed of vascular endothelial cells and perivascular astrocytes that restrict the passage of immunocompetent cells into the central nervous system (CNS). Expression of the adhesion molecules, intercellular adhesion molecule 1 (ICAM-1) and vascular cell adhesion molecule-1 (VCAM-1) on brain microvascular endothelial cells (BMVEC) and their interaction with human immunodeficiency virus (HIV-1) viral proteins may help enhance viral adhesion and virus-cell fusion resulting in increased infectivity. Additionally, transmigration through the $\mathrm{BBB}$ is facilitated by both endothelial and monocyte/macrophage-derived nitric oxide (NO). Dysregulated production of NO by BMVEC due to opiates and HIV-1 viral protein interactions play a pivotal role in brain endothelial injury, resulting in the irreversible loss of BBB integrity, which may lead to enhanced infiltration of virus-carrying cells across the BBB. Opioids act as co-factors in the neuropathogenesis of HIV-1 by facilitating BBB dysfunction however, no studies have been done to investigate the role of opiates alone or in combination with HIV-1 viral proteins on adhesion molecule expression in BMVEC. We hypothesize that opiates such as heroin and morphine in conjunction with the HIV-1 viral protein gp120 increase the expression of adhesion molecules ICAM- 1 and VCAM-1 and these effects are mediated via the modulation of NO. Results show that opiates alone and in synergy with gp120 increase both the genotypic and phenotypic expression of ICAM-1 and VCAM-1 by BMVEC, additionally, these opiate induced effects may be the result of increased NO production. These studies will provide a better understanding of how opiate abuse in conjunction with HIV-1 infection facilitates the breakdown of the BBB and exacerbates the neuropathogenesis of HIV-1. Elucidation of the mechanisms of BBB modulation will provide new therapeutic approaches to maintain BBB integrity in $\mathrm{HIV}-1^{+}$opiate abusing patient populations.
\end{abstract}

Key words: Blood brain barrier; opiates; adhesion molecules

\section{INTRODUCTION}

The Blood Brain Barrier (BBB) is composed of brain microvascular endothelial cells (BMVEC), a collagen matrix and astrocytes. Astrocytic endfeet surround the BMVEC abluminal surface and influence the 'tightness' and trafficking role of the barrie ${ }^{[1]}$. BMVEC produce inflammatory factors that modulate the expression of adhesion molecules and BBB permeability thereby facilitating cell trafficking into the central nervous system $(\mathrm{CNS})^{[2]}$. In human immunodeficiency virus (HIV-1) infected patients, there is a breech in the BBB which permits the influx of HIV-1 viral proteins ${ }^{[3-5]}$. The cellular processes involved in the neuropathogenesis of HIV-1 infection suggest an interaction between monocytes/macrophages and BMVEC, where the migration of the monocytes/macrophages in the CNS is mainly mediated via the endothelial adhesion molecules vascular cell adhesion molecule-1 (VCAM-1), intercellular adhesion molecule 1 (ICAM-1) and E-Selectin ${ }^{[6-8]}$. The ability of HIV-1 to bind to permissive cells is crucial for subsequent viral replication. Expression of ICAM-1 on BMVEC and its interaction with HIV-1 viral proteins may help enhance viral adhesion and virus-cell fusion resulting in increased infectivity ${ }^{[9,10]}$. Additionally, transmigration through the BBB is facilitated by both endothelial and monocyte/macrophage-derived nitric oxide (NO), chemokines, as well as by increased production of matrix metalloproteinase activity by not only the transmigration cells but also by the BMVEC and astrocytes ${ }^{[11]}$.

Several studies have indicated an increased frequency of HIV-1 dementia among the HIV-1 infected population that abuse intravenous drugs. Recent studies by ${ }^{[12]}$ suggest that injection drug users who abuse heroin are at increased risk of CNS complications associated with HIV-1 infection. An

Corresponding Author:

Madhavan PN Nair, Ph.D. Professor, Department of Medicine, Div of Allergy, Immunology and Rheumatology, 310 Multi Research Bldg, Buffalo General Hospital, 100 High Street, Buffalo, NY 14203, Tel: 716859 2994, Fax: 7168592999 
opiate drug such as heroin via its active metabolite diacetylmorphine plays a critical role in the regulation of immune responses and exacerbates the immunosuppressive consequences of HIV -1 . However, the mechanisms by which opiates increase the neuropathogenesis of HIV-1 remain uncertain.

Although monocytes and macrophages are the predominant HIV-1 infected cells in CNS tissue, studies of brain sections of acquired immune deficiency syndrome (AIDS) patients have identified HIV-1 infection of BMVEC. HIV-1 infection of BMVEC may contribute to CNS dysfunction via altering the structural and functional properties of the brain microvasculature, thereby affecting the BBB integrity. Up-regulation of adhesion molecule expression on BMVEC could permit entry of HIV-1 into the CNS. Both VCAM-1 and ICAM-1 play an important role for many cell-contact-dependent immune functions and increased expression of these molecules on the endothelial surface as well as high circulating levels of these molecules in HIV-1 positive individuals could contribute to neuroimmune dysfunction ${ }^{[13,14]}$.

Opioids act as co-factors in the neuropathogenesis of HIV-1 by facilitating BBB dysfunction and although several previous studies including our own ${ }^{[15-19]}$ suggest that opiates alone and in combination with HIV-1 viral proteins exacerbate the neuropathogenesis of HIV-1, no studies have been done to investigate the role of opiates alone or in combination with HIV-1 viral proteins on adhesion molecule expression in BMVEC. The goals of these studies were to investigate 1) if opiates alone and in conjunction with HIV-1 proteins enhance transmigration across the artificial in vitro $\mathrm{BBB}, 2$ ) if opiates alone and/or in conjunction with HIV-1 proteins modulate the expression of adhesion molecules ICAM1 and VCAM-1 in BMVEC and 3) if NO expression is involved in these opiate mediated effects. These studies will provide a better understanding of how opiate abuse in conjunction with HIV-1 infection facilitates the breakdown of the BBB and exacerbates the neuropathogenesis of HIV-1. Further, elucidation of the mechanisms of BBB modulation will provide new therapeutic approaches to maintain $\mathrm{BBB}$ integrity in $\mathrm{HIV}-1^{+}$opiate abusing patient populations.

\section{MATERIALS AND METHODS}

Human subjects: Blood donors were apprised of this study and consents were obtained consistent with the policies of SUNY Buffalo and the National Institutes of Health. Human peripheral blood mononuclear cells (PBMCs) were isolated from $60 \mathrm{ml}$ of blood obtained from donors, using the Ficoll Hypaque gradient technique.

In vitro cell culture experiments: $B M V E C$ were cultured at a concentration of $1 \times 10^{6}$ cells $\mathrm{mL}^{-1}$ with heroin $\left(10^{-7}\right.$ to $\left.10^{-11} \mathrm{M}\right)$ alone or morphine $\left(10^{-7} \mathrm{M}\right)$ alone or in combination with gp120 (100 ng mL $\left.\mathrm{mL}^{-1}\right)$ in 6 well plates for $48 \mathrm{hr}$. Heroin was obtained as a lyophilized protein and dissolved in culture media (Cat \# H5144, Sigma Chemical Co; St Louis, MO). Morphine sulfate (AstraZeneca, NJ) was obtained as a $10 \mathrm{mg} \mathrm{mL}^{-1}$ stock solution in saline. HIV-1 gp120 [recombinant] (M-tropic strain, Bal), derived from a Chinese hamster ovary $(\mathrm{CHO})$ cell expression system (Chiron Corp., Emeryville, CA) was obtained as a lyophilized powder which was dissolved in $1 \mathrm{ml}$ of PBS. Appropriate dilutions of stock solutions for use in culture were made in culture media. Gp120 was used at $100 \mathrm{ng} \mathrm{mL} \mathrm{mL}^{-1}$ which is similar to levels found in vivo during active infection with HIV-1 ${ }^{[20,21]}$.

Treatment of PBMC with HIV-1 isolates: PBMC were infected with HIV-1 IIIB [X4] (NIH AIDS Research and Reference Reagent Program Cat\# 398) at a concentration of $10^{3.0}$ TCID ${ }_{50} / \mathrm{ml}$ cells for $3 \mathrm{hr}$. Cells were washed and cultured \pm Morphine $\left(10^{-7} \mathrm{M}\right)$ for 48 hr. The infected PBMC were then used in a transmigration assay described below. The culture supernatants were quantitated for p24 antigen and the levels indicate a significant degree of infection in these PBMC cultures (data not shown).

Blood-brain barrier model: The BBB model is established in our laboratory using primary human BMVEC and normal human astrocytes (NHA). Primary cultures of both human BMVEC and NHA to constitute the BBB were obtained from Applied Cell Biology Research Institute (ACBRI) Kirkland, WA. Characterization of the BMVEC indicated $>95 \%$ of these cells were positive for cytoplasmic VWF/Factor VIII. NHA cultures were $>99 \%$ glial fribrillary acidic protein (GFAP) positive. Both NHA and BMVEC were initially propagated in a $25 \mathrm{~cm}^{2}$ culture flasks using Astrocyte Basal Medium (ABCRI) and 10\% fetal bovine serum for NHA and CS-C complete medium (CSC catalog SF-4Z0-500) for BMVEC. The BBB model used consists of 2-compartment wells in a culture plate with the upper compartment separated from the lower by a 3 micron PET insert on which the BMVEC cells are grown to confluency on the upper side while a confluent layer of human astrocytes are grown on the underside. Formation of a BBB takes a minimum of 5 days.

Transmigration assay: All transmigration experiments are conducted using well established protocols ${ }^{[2,23]}$ on day 6 of BBB culture after membrane integrity has been established by TEER measurement and permeability to inulin. Transmigration assays were done in presence and absence of a chemotactic gradient. The chemoattractant used was recombinant RANTES (10 ng $\mathrm{mL}^{-1}$ ) added to the lower chamber just prior to the start of the transmigration assay. The artificial BBB was treated with heroin $\left(10^{-7} \mathrm{M}\right)$ alone/ and morphine $\left(10^{-7}\right.$ 
M) alone and /or gp120 (100 $\left.\mathrm{ng} \mathrm{mL}^{-1}\right)$ for $24 \mathrm{hr}$ prior to the transmigration assay. PBMC $\left(5 \times 10^{5}\right.$ cells $)$ are added per well into the upper chamber of a 6 well plate, the chambers are then incubated for $3 \mathrm{hr}$ at $37^{\circ} \mathrm{C}$, in $5 \%$ $\mathrm{CO}_{2}$ after which the contents of the lower chamber are collected after scraping the bottom well. Appropriate controls, which include insert only, insert with astrocytes only, inserts with endothelial cells only to compare with co-cultures as well as co-cultures with and without the addition of chemokine RANTES as chemoattractant were used. Percent transmigration was calculated with respect to the initial total number of cells added to the upper chamber by counting the cells using a hemocytometer. Cell viability was assessed by trypan blue staining. The viability of the transmigrated cells for all the experiments in the study was $>90 \%$.

RNA extraction: Cytoplasmic RNA was extracted by an acid guanidinium-thiocyanate-phenol-chloroform method as described ${ }^{[24]}$. Cultured cells were centrifuged and resuspended in a $4 \mathrm{M}$ solution of guanidinium thiocynate. Cells were lysed by repeated pipetting and then phenol-chloroform extracted in the presence of sodium acetate. After centrifugation, RNA was precipitated from the aqueous layer by adding an equal volume of isopropanol and the mixture was kept at $-20^{\circ}$ $\mathrm{C}$ for $1 \mathrm{hr}$ and then centrifuged to sediment the RNA. The RNA pellet was washed with $75 \%$ ethanol to remove any traces of guanidinium and DNAse $\left(1 \mathrm{U} \mathrm{mg}^{-1}\right.$ RNA) treated to remove any DNA contamination. The final pellet was dried and resuspended in diethyl pyrocarbonate (DEPC) water and the amount of RNA determined using a spectrophotometer at $260 \mathrm{~nm}$. Purified RNA was kept at $-70^{\circ} \mathrm{C}$ until used.

Real time quantitative PCR (Q-PCR): Relative abundance of each mRNA species is quantitated using real time quantitative PCR. To provide precise quantification of initial target in each PCR reaction, the amplification plot is examined at a point during the early $\log$ phase of product accumulation. This is accomplished by assigning a fluorescence threshold above background and determining the time point at which each sample's amplification plot reaches the threshold (defined as the threshold cycle number or $\mathrm{C}_{\mathrm{T}}$ ). Differences in threshold cycle number are used to quantify the relative amount of PCR target contained within each tube. Relative expression of mRNA species is calculated using the comparative $\mathrm{C}_{\mathrm{T}}$ method. All data are controlled for quantity of RNA input by performing measurements on an endogenous reference gene, $\beta$ actin. In addition, results on RNA from treated samples are normalized to results obtained on RNA from the control untreated sample. Briefly, the analysis is performed as follows: for each sample, a difference in $\mathrm{C}_{\mathrm{T}}$ values $\left(\Delta \mathrm{C}_{\mathrm{T}}\right)$ was calculated for each mRNA by taking the mean $\mathrm{C}_{\mathrm{T}}$ of duplicate tubes and subtracting the mean $\mathrm{C}_{\mathrm{T}}$ of the duplicate tubes for the reference
RNA ( $\beta$-actin) measured on an aliquot from the same RT reaction. The $\Delta C_{T}$ for the treated sample was then subtracted from the $\Delta C_{T}$ for the untreated control sample to generate a $\Delta \Delta C_{T}$. The mean of these $\Delta \Delta C_{T}$ measurements was then used to calculate expression of the test gene relative to the reference gene and normalized to the untreated control as follows: Relative Expression/Transcript Accumulation Index $=2-\Delta \Delta \mathrm{cT}$. This calculation assumes that all PCR reactions are working with $100 \%$ efficiency ${ }^{[25]}$.

FACS analysis: Immunofluorescent staining was used to identify and quantify the number of BMVEC expressing the surface markers, VCAM-1 and ICAM-1 in response to treatment with heroin. Approximately $1 \times 10^{6}$ BMVEC cells were treated with $\left(10^{-7}\right.$ to $\left.10^{-11} \mathrm{M}\right)$ heroin alone for $24 \mathrm{hr}$ and cells were harvested, trypsinized, washed and suspended in staining buffer. FACS conditions were optimized by adjusting the settings for photomultiplier tube voltage and compensation using appropriate cell surface staining controls and quadrant markers were set using a specified isotype control for the flurochromeconjugated antibody used. Monoclonal antibodies (mAbs) against VCAM-1 (Cat \# BBA22; R\&D Systems, Inc) and ICAM-1 (Cat \# BBA20; R\&D Systems, Inc) both of which were conjugated to FITC and the matched isotype controls $\left(\operatorname{IgG}_{2 \mathrm{~A}}\right.$ and $\mathrm{IgG}_{1}$ respectively) were obtained from $R \& D$ Systems, Inc. For both VCAM-1 and ICAM-1 surface marker analysis, Fc receptors were pre-blocked by incubating cells with an excess of human purified IgG and then stained with $0.5 \mu \mathrm{g}$ of FITC-conjugated $\mathrm{mAb}$ specific for either cell surface antigen VCAM-1 and ICAM-1. Cells were washed twice with staining buffer, centrifuged at $250 \times \mathrm{g}$ and the supernatant fluid removed. Cells were then washed in PBS, fixed and resuspended in staining buffer prior to flow cytometry using a FACS Calibur instrument (BD Biosciences, San Jose, CA). Stained cells were subjected to light scatter analysis and a fixed population of cells were gated after quandrant markers were set, based on the isotype control and represented as FL-1 (FITC-labeled) on the $\mathrm{X}$ axis. Cells positive for VCAM-1 and ICAM-1 were expressed as a percentage of the total cells gated.

ELISA: VCAM-1 and ICAM-1 $\square$ protein secretion into culture supernates was quantitated using ELISA (Biosource International Inc) kits as described by the manufacturer. sVCAM-1 ELISA (Cat \# KHT0611) and sICAM-1 ELISA (Cat \# KHS5411) were both enzymelinked immunosorbent assays for the quantitative detection of soluble human vascular cell adhesion molecule-1 and soluble human intracellular adhesion molecule-1 in cell culture supernatants, respectively. The sensitivity of the VCAM-1 assay was $0.9 \mathrm{ng} \mathrm{mL}^{-1}$ 
and the assay range was $10-80 \mathrm{ng} \mathrm{mL}^{-1}$. The sensitivity of the ICAM-1 assay was $0.5 \mathrm{pg} \mathrm{mL}^{-1}$ and assay range: $0.625-10 \mathrm{ng} \mathrm{mL}^{-1}$.

Total nitric oxide assay: NO levels in BMVEC culture supernatants were measured using a colometric assay. This assay determines total NO based on the enzymatic conversion of nitrate to nitrite by nitrate reduction. The reaction was followed by a colorimetric detection of nitrite as an azo product of the Griess reaction. Briefly, $50 \mu \mathrm{l}$ of culture supernatants or standard was added to $50 \mu \mathrm{l}$ of reaction buffer in a 96 well plate. This was followed by the addition of $25 \mu \mathrm{l}$ of NADH and $25 \mu \mathrm{l}$ of nitrate reductase. The plate was then incubated at $37^{\circ} \mathrm{C}$ for $30 \mathrm{~min}$. After incubation, $50 \mu \mathrm{l}$ each of griess reagent I \& II were consequently added to all wells except the blanks. After an incubation period of $10 \mathrm{~min}$ at RT, the OD is determined at $540 \mathrm{~nm}$ using a microplate reader (MicroQuant, Biotek). The concentrations of NO in the test samples were determined by comparing the OD values of the curve generated with the standards. The sensitivity of the total $\mathrm{NO}$ assay is $<1.35 \mu \mathrm{M} \mathrm{mL}^{-1}$.

\section{RESULTS}

Effect of opiates on transmigration of PBMC across an in vitro BBB: The effect of opiates $\pm \mathrm{gp} 120$ (100 ng $\mathrm{mL}^{-1}$ ) on transmigration of PBMC from healthy donors across the BBB was investigated. Data shown in Fig. 1 demonstrate that treatment of the BBB with heroin $\left(10^{-7}\right.$ $\mathrm{M})$ and morphine $\left(10^{-7} \mathrm{M}\right)$ increased transmigration of PBMC by $36 \% \quad(\mathrm{p}<0.01)$ and $35 \% \quad(\mathrm{p}<0.01)$, respectively. Treatment of the BBB with gp120 (100 ng $\left.\mathrm{mL}^{-1}\right)$ increases transmigration by $18 \%(\mathrm{p}<0.05)$ and treatment with morphine $\left(10^{-7} \mathrm{M}\right)$ plus gp120 (100 ng $\left.\mathrm{mL}^{-1}\right)$ increased transmigration by $49 \%(\mathrm{p}<0.001)$.

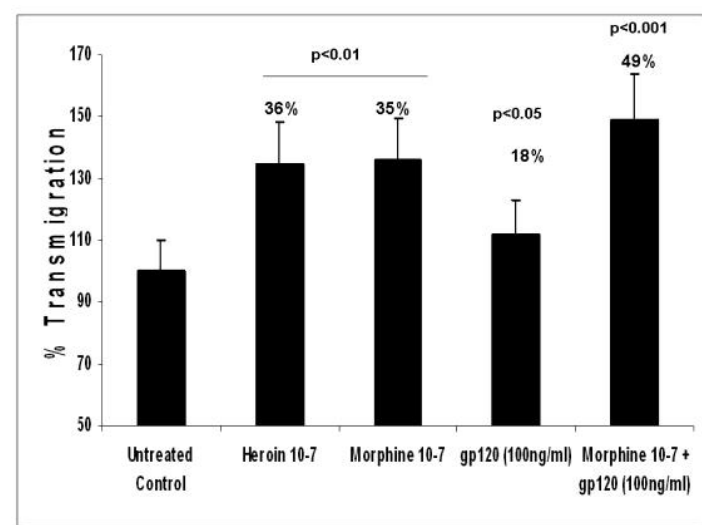

Fig. 1: Effect of opiates and/or gp120 on Transmigration of PBMC across the BBB. BBB was treated with heroin $\left(10^{-}\right.$ $\left.{ }^{7} \mathrm{M}\right) /$ morphine $\left(10^{-7} \mathrm{M}\right)$, gp120 (100 $\left.\mathrm{ng} \mathrm{mL}^{-1}\right)$ and morphine + gp120 for $24 \mathrm{hrs}$ followed by a transmigration assay. The percentage of cells that transmigrated across the BBB with respect to the untreated control was calculated. Data are the mean $\pm \mathrm{SD}$ of 3 separate experiments done in triplicate. Statistical significance was determined by Students' ' $t$ ' test

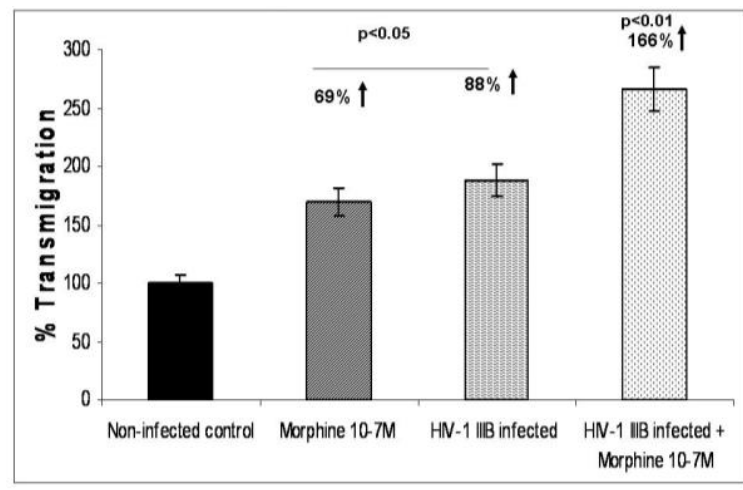

Fig. 2: Effect of morphine and/or HIV-1 infection on Transmigration of PBMC across the BBB. PBMC treated with Morphine (10$7 \mathrm{M}$ ) and/or HIV-1 IIIB overnight were used in a transmigration assay. The percentage of cells that have transmigrated across the BBB with respect to the untreated control was calculated. Data are the mean \pm SD of 3 separate experiments done in triplicate. Statistical significance was determined by Students' ' $t$ ' test.

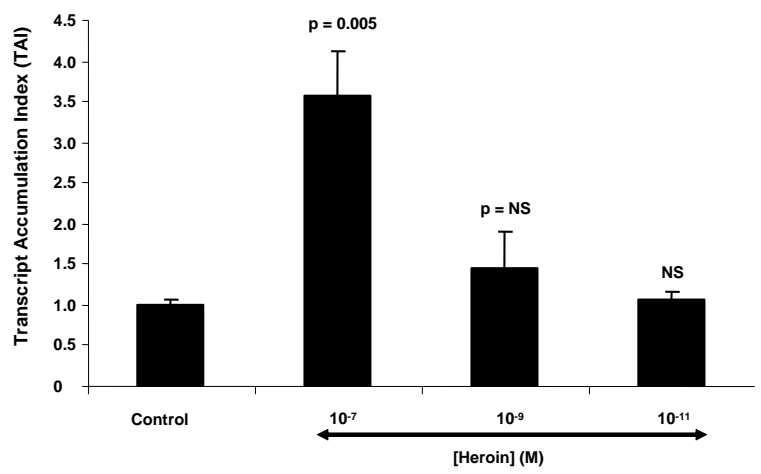

Fig. 3: Heroin increased ICAM-1 gene expression. BMVEC were treated with heroin $\left(10^{-7}\right.$ to $\left.10^{-11} \mathrm{M}\right)$ for $48 \mathrm{hr}$. RNA was extracted, reverse transcribed and followed by quantitative real time PCR against the ICAM-1 and the housekeeping gene $\beta$-actin primers. The data represent mean \pm SD of 3 independent experiments. Statistical analysis was done using Students' 't'-test.

Effect of morphine and /or HIV-1 infection on transmigration of PBMC across the BBB: PBMC treated with morphine $\left(10^{-7} \mathrm{M}\right)$ and/ HIV-1 IIIB $\left(10^{3.0}\right.$ TCID $50 \mathrm{~mL}^{-1}$ cells overnight) were used in a transmigration assay. The percentage of cells that transmigrated across the $\mathrm{BBB}$ with respect to the untreated control was calculated. Results show a $69 \%$ percent increase in transmigration of morphine treated PBMC, while an $88 \%$ increase in the HIV-1 infected PBMC occurred (Fig. 2). Further, when HIV-1 infected PBMC treated with morphine were used in the transmigration assay, transmigration was further increased to $166 \%$. These results indicate that HIV-1 in combination with morphine alters BBB permeability thereby enhancing transmigration (Fig. 2)

Effect of Heroin on ICAM-1 and VCAM-1 gene expression by BMVEC: ICAM-1 (CD54) is a $90-\mathrm{kDa}$ glycoprotein expressed on the surface of several cell 


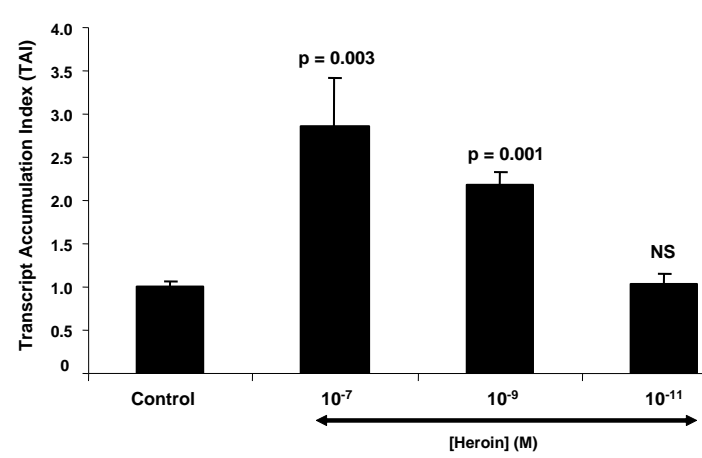

Fig. 4: Heroin increased VCAM-1 gene expression. BMVEC were treated with heroin $\left(10^{-7}\right.$ to $\left.10^{-11} \mathrm{M}\right)$ for $48 \mathrm{hr}$. RNA was extracted, reverse transcribed and followed by quantitative real time PCR against VCAM-1 and the housekeeping gene $\beta$-actin primers. The data represent the mean \pm SD of 3 independent experiments. Statistical analysis was done using Students' ' $t$ '-test

Effect of Heroin on ICAM-1 expression in BMVEC
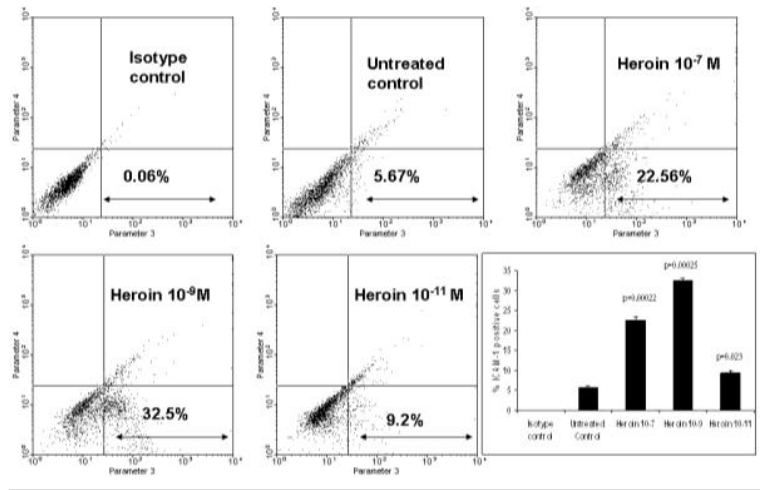

Fig. 5: Heroin increased the phenotypic expression of ICAM-1. BMVEC were treated with heroin $\left(10^{-7}\right.$ to $\left.10^{-11} \mathrm{M}\right)$ for $48 \mathrm{hr}$. FACS analysis was done to determine the percentage of cells expressing ICAM-1. FACS plots are from a representative experiment, while the histogram is a graphical representation of 3 independent FACS experiments. Statistical significance was calculated by Students' 't'-test.

types, including leukocytes and endothelial cells. ICAM-1 has an important role in migration of leukocytes to sites of inflammation, enabling the firm adhesion and diapedesis of leukocytes ${ }^{[13,14,26,27]}$. VCAM-1 is a $110-\mathrm{kDa}$ cell adhesion molecule which is a receptor for ${ }_{4} \beta_{1}$ integrin (VLA-4) expressed on the surface of activated mononuclear cells. It is also expressed on the endothelial cells and its levels have been shown to increase adhesiveness and migration $^{[28,29]}$. Studies have shown that ligation of ICAM-1 on the surface of resting human endothelial cells can lead to the expression of VCAM-1. We examined if heroin treatment modulated the gene expression of ICAM-1 and VCAM-1 in BMVEC. BMVEC were cultured with different concentrations of heroin $\left(10^{-7}\right.$ to $\left.10^{-11} \mathrm{M}\right)$ for $48 \mathrm{hr}$, RNA was extracted, reverse transcribed and cDNA amplified by PCR using primers specific for the housekeeping gene, $\beta$-actin,
Effect of Heroin on VCAM-1 expression in BMVEC
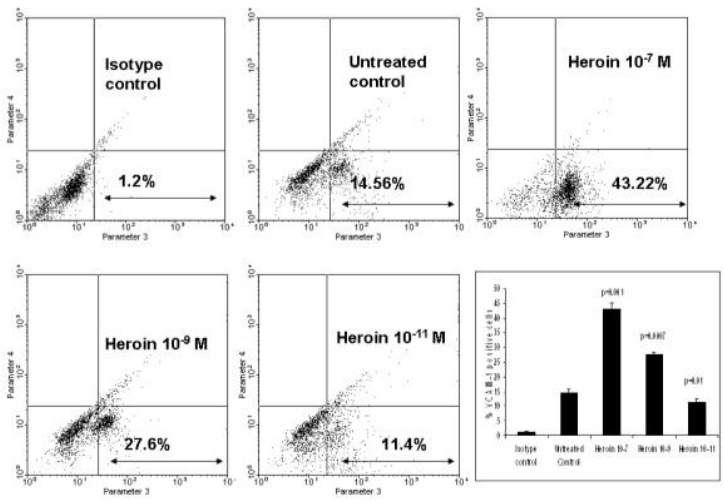

Fig. 6: Heroin increased the phenotypic expression of VCAM-1. BMVEC were treated with heroin $\left(10^{-7}\right.$ to $\left.10^{-11} \mathrm{M}\right)$ for $48 \mathrm{hr}$. FACS analysis was done to determine the percentage of cells expressing VCAM-1. FACS plots are from a representative experiment, while the histogram is a graphical representation of 3 independent FACS experiments. Statistical significance was calculated by Students' ' $\mathrm{t}$ '-test

ICAM-1 and VCAM-1 using real-time, quantitative PCR. Data shown in Fig. 3 demonstrate that heroin at $10^{-7}$ significantly up regulated ICAM-1 gene expression $\mathrm{TAI}=3.57 \pm 0.56(257 \%$ increase, $\mathrm{p}=0.005)$, while no significant modulation at $10^{-9}(\mathrm{TAI}=1.45 \pm 0.46 ; \mathrm{p}=$ NS) and $10^{-11} \mathrm{M}($ TAI $=1.05 \pm 0.11 \mathrm{p}=\mathrm{NS})$ was observed as compared to control cultures (TAI $=1.00 \pm$ $0.05)$. Figure 4 demonstrates that heroin at $10^{-7}(\mathrm{TAI}=$ $2.84 \pm 0.56(184 \%$ increase, $\mathrm{p}=0.003)$ and $10^{-9}(\mathrm{TAI}=$ $2.14 \pm 0.12 ;(114 \%$ increase, $\mathrm{p}=0.001)$ significantly up regulated VCAM-1 gene expression while no significant modulation was observed at $10^{-11} \mathrm{M}(\mathrm{TAI}=$ $1.04 \pm 0.11, \mathrm{p}=\mathrm{NS}$ ) compared to control cultures (TAI $=1.00 \pm 0.06$ ).

Effect of Heroin on the phenotypic expression of ICAM-1 and VCAM-1 by BMVEC: BMVEC were cultured with heroin $\left(10^{-7}\right.$ to $\left.10^{-11} \mathrm{M}\right)$ for $48 \mathrm{hr}$, cells were harvested, washed and stained with FITC labeled VCAM-1 and ICAM-1 antibodies prior to flow cytometry analysis using the FACS Calibur instrument. FACS analysis data show that heroin treatment significantly increased the percentage of cells expressing both ICAM-1 and VCAM- 1 . The percentage of ICAM-1 expressing cells at $10^{-7}, 10^{-9}$ and $10^{-11} \mathrm{M}$ heroin concentrations were $22.56 \%(\mathrm{p}=0.00022)$, $32.56 \%(\mathrm{p}=0.00025)$ and $9.23 \%(\mathrm{p}=0.02)$ respectively as compared to the untreated control (5.67\%) (Fig. 5). While the percentage of VCAM-1 expressing cells at $10^{-7}, 10^{-9}$ and $10^{-11} \mathrm{M}$ heroin concentrations were $43.21 \%(\mathrm{p}=0.001), 27.60 \%(\mathrm{p}=$ $0.0007)$ and $11.4 \% \mathrm{p}=0.01$ ) respectively as compared to the untreated control (14.57\%) (Fig. 6).

Effect of heroin and gp120 on protein expression of ICAM-1 and VCAM-1 by BMVEC: The protein levels of ICAM-1 and VCAM-1 were measured in the culture supernatants of BMVEC treated with heroin 


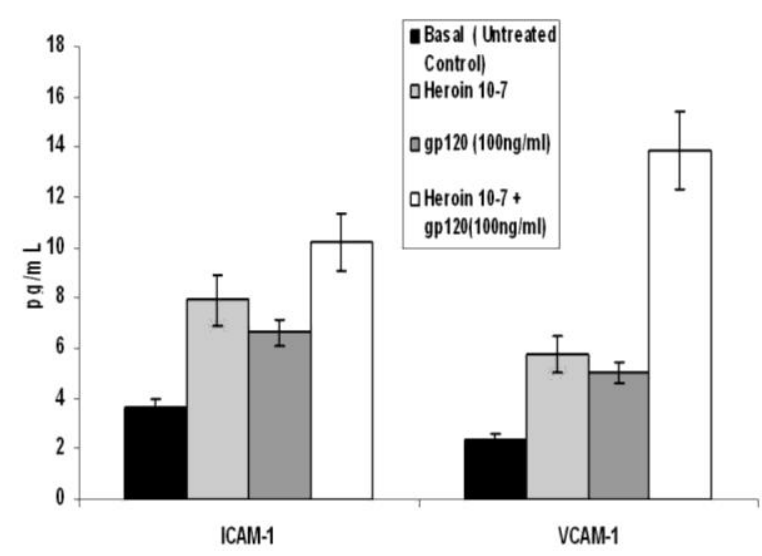

Fig. 7: Heroin and/or gp120 increased VCAM-1 and ICAM-1 production by BMVEC. BMVEC were treated with heroin $\left(10^{-7} \mathrm{M}\right)$ and/or gp120 (100 ng mL $\left.{ }^{-1}\right)$ for $72 \mathrm{hr}$. Culture supernatants were harvested and quantitated for ICAM-1 and VCAM-1 levels using commercially available ELISA kits. The data represent the mean \pm SD of 3 independent experiments. Statistical analysis was done using Students' ' $\mathrm{t}$ '-test

Table 1: Heroin increased NO production by BMVEC. BMVEC were treated with heroin $\left(10^{-7}\right.$ to $\left.10^{-9} \mathrm{M}\right)$ and/ or gp120 (100 ng mL $\mathrm{m}^{-1}$ ) for $48 \mathrm{hr}$. NO levels were quantitated in the culture supernatants using the colorimetric assay as described in the materials and methods section. The data represent mean $\pm \mathrm{SD}$ of 3 independent experiments. Statistical analysis was done using Students' 't'-test

\begin{tabular}{lll}
\hline Treatments & $\mathrm{NO} \mu \mathrm{M} \mathrm{L}^{-1}$ & $\mathrm{p}$ value \\
\hline Control & $3.6 \pm 0.56$ & \\
Heroin $10^{-7} \mathrm{M}$ & $12.6 \pm 0.75$ & 0.003 \\
Heroin $10^{-9} \mathrm{M}$ & $12.9 \pm 1.63$ & 0.002 \\
gp120 $\left(100 \mathrm{ng} \mathrm{mL} \mathrm{mL}^{-1}\right)$ & $8.3 \pm 0.36$ & 0.004 \\
Heroin $10^{-7} \mathrm{M}+\mathrm{gp} 120\left(100 \mathrm{ng} \mathrm{mL}^{-1}\right)$ & $17.4 \pm 0.59$ & 0.0003 \\
Heroin $10^{-9} \mathrm{M}+\mathrm{gp} 120\left(100 \mathrm{ng} \mathrm{mL}{ }^{-1}\right)$ & $14.1 \pm 1.18$ & 0.002 \\
\hline p values are calculated using Student's " $t$-test" comparing $\mathrm{NO}$ \\
production between treated and untreated control cultures.
\end{tabular}

$\left(10^{-7} \mathrm{M}\right)$ and/ or gp120 $\left(100 \mathrm{ng} \mathrm{mL} \mathrm{L}^{-1}\right)$. Note that in the combination experiments, heroin $\left(10^{-7} \mathrm{M}\right)$ was the optimal dose at which the maximal effect of heroin were observed based on gene expression data and gp120 was used at the highest non toxic dose of $100 \mathrm{ng}$ $\mathrm{mL}^{-1}$. Figure 7 shows ICAM-1 and VCAM-1 protein secretion data. Heroin $\left(10^{-7} \mathrm{M}\right)$ treatment significantly increased ICAM-1 protein expression $(7.91 \pm 0.23$, $\mathrm{p}<0.03)$; gp120 (100 $\left.\mathrm{ng} \mathrm{mL}^{-1}\right)$ treatment also increased ICAM-1 protein expression $(6.62 \pm 0.25, \mathrm{p}<0.05)$ while a combination of heroin $\left(10^{-7} \mathrm{M}\right)$ and gp120 (100 ng $\left.\mathrm{mL}^{-1}\right)$ showed an additive effect $(10.23 \pm 0.54, \mathrm{p}<0.01)$ on ICAM-1 production. Additionally, heroin $\left(10^{-7} \mathrm{M}\right)$ treatment significantly increased VCAM-1 protein expression $(5.77 \pm 0.15, \mathrm{p}<0.05)$; gp120 $\left(100 \mathrm{ng} \mathrm{mL}^{-1}\right)$ treatment also increased VCAM-1 protein expression $(5.01 \pm 0.09, \mathrm{p}<0.05)$ while a combination of heroin $\left(10^{-7} \mathrm{M}\right)$ and gp120 $\left(100 \mathrm{ng} \mathrm{mL}^{-1}\right)$ showed a synergistic effect $(13.85 \pm 0.42, \mathrm{p}<0.001)$ on VCAM-1 production which was $5.1 \mathrm{pg}$ higher than the cumulative values of heroin (5.7) and gp120 (5.1) treated cultures.

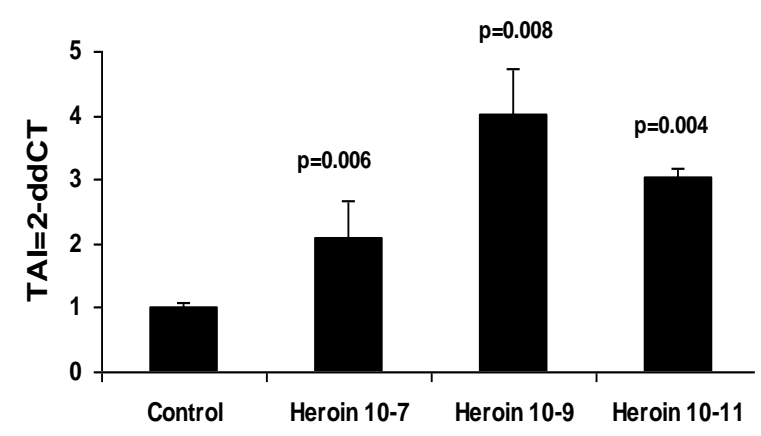

Fig. 8: Heroin increased iNOS gene expression. BMVEC were treated with heroin $\left(10^{-7}\right.$ to $\left.10^{-11} \mathrm{M}\right)$ for $48 \mathrm{hr}$. RNA was extracted, reverse transcribed and followed by quantitative real time PCR against iNOS and the housekeeping gene $\beta$ actin primers. The data represent mean \pm SD of 3 independent experiments. Statistical analysis was done using Students' ' $t$ '-test

Effect of Heroin on iNOS gene expression by BMVEC: NO has been implicated in the regulation of BBB permeability. NO synthases (NOS) is a constitutively expressed enzyme that modulates many physiological functions ${ }^{[19,30]}$. iNOS is calciumindependent and inducible which can be stimulated by stress, inflammation and infection ${ }^{[30,31]}$. We examined whether heroin treatment could modulate the iNOS gene expression. BMVEC were cultured with heroin $\left(10^{-7}\right.$ to $\left.10^{-11} \mathrm{M}\right)$ for $48 \mathrm{hr}$, RNA was extracted, reverse transcribed and cDNA amplified by Q-PCR using primers specific for the housekeeping gene, $\beta$-actin and iNOS. Figure 8 shows that heroin at $10^{-7}(\mathrm{TAI}=2.11 \pm$ $0.16111 \%$ increase, $\mathrm{p}=0.006), 10^{-9}(\mathrm{TAI}=4.03 \pm$ $0.70 ; 303 \%$ increase; $\mathrm{p}=0.008)$ and $10^{-11} \mathrm{M}(\mathrm{TAI}=$ $3.05 \pm 0.11205 \%$ increase; $p=0.004)$ significantly upregulated iNOS gene expression as compared to control cultures (TAI $=1.00 \pm 0.08)$. These results indicate that the heroin can induce $\mathrm{NO}$ production which may modulate BBB permeability.

Effect of Heroin and/or gp120 on NO production by BMVE: Data presented in Table 1 shows the effect of heroin and/or gp120 on NO production. Results show that heroin at $10^{-7}\left(12.6 \pm 0.75 \mu \mathrm{M} \mathrm{L}^{-1}, \mathrm{p}<0.003\right)$ and $10^{-9} \mathrm{M}\left(12.9 \pm 1.63 \mu \mathrm{M} \mathrm{L}^{-1}, \mathrm{p}<0.002\right)$ significantly increased NO production by BMVECs; gp120 (100 ng $\left.\mathrm{mL}^{-1}\right)$ also $\left(8.4 \pm 0.36 \mu \mathrm{M} \mathrm{L}^{-1}, \mathrm{p}<0.004\right)$ increased NO production, however a combination of heroin $10^{-7}$ or $10^{-9} \mathrm{M}$ plus gp120 (100 $\left.\mathrm{ng} \mathrm{mL}^{-1}\right)$ showed a significant additive effect on NO production with values of (17.4 \pm $\left.0.59 \mu \mathrm{M} \mathrm{L}^{-1}, \mathrm{p}<0.0003\right)$ and $\left(14.1 \pm 1.18 \mu \mathrm{M} \mathrm{L}^{-1}\right.$, $\mathrm{p}<0.002)$ respectively.

\section{DISCUSSION}

To invade the CNS, HIV-1 must migrate through the BMVECs that compose the BBB. HIV-1 
encephalopathy often exhibits impairment of BBB integrity ${ }^{[1,32]}$. The pathogenesis of HIV-1 associated dementia (HAD) can be primarily attributed to infiltration of the CNS by HIV-1 infected mononuclear cells ${ }^{[33]}$. The endothelial $\mathrm{BBB}$ has a critical role in controlling lymphocyte traffic into the CNS, both under physiological conditions and disease states. The BBB plays a crucial role in CNS homeostasis, serving as the brain's protective shield against the entry of cells and soluble factors from blood to brain ${ }^{[34]}$. The transmigration of HIV-1 infected monocytes and lymphocytes across the $\mathrm{BBB}$ into the $\mathrm{CNS}$ is thought to be a pre-requisite for the development of $\mathrm{HAD}^{[33]}$. Increased permeability of the $\mathrm{BBB}$ is an early and critical event that often precedes symptoms of HAD and HIV-1 gains entry into the brain predominantly via cell-associated transmigration across the $\mathrm{BBB}^{[34]}$. Our results show that morphine and $\mathrm{HIV}-1$ infected PBMC show increased transmigration across the BBB.

Adhesion molecules regulate the transmigration of blood leukocytes across the BBB. Increased expression of adhesion molecules by endothelial cells correlates with the extent of leukocyte infiltration into the brain. HIV-1 infection leads to elevated levels of proinflammatory cytokines such as TNF- $\alpha$ and IL-1 $\beta$ secreted by infected monocytes which induce the expression of endothelial adhesion molecules such as ICAM-1 and VCAM-1 by the BMVEC that facilitates rolling and binding of leukocytes ${ }^{[9]}$. ICAM-1 has an important role in leukocytes migration, adhesion and diapedesis $^{[14]}$. VCAM-1 is a $110-\mathrm{kDa}$ cell adhesion molecule that is a receptor for $\alpha_{4} \beta_{1}$ integrin (VLA-4) expressed on the surface of endothelial cells and is known to increase adhesiveness and migration ${ }^{[28,29]}$ Woodman et al have reported that HIV-1 viral proteins induced astrocyte VCAM-1 and ICAM-1 expression in a dose and time dependent manner ${ }^{[35]}$ HIV-1 viral protein tat can activate human endothelial cells to induce the expression of various adhesion molecules that may play a role in the extravasation of HIV-1 infected cells. Studies have shown that ICAM-1 expression in HIV-1-infected cells is polarized on both isolated cells and syncytia, co-localizing with HIV-1 matrix protein and this process of cell to cell contact is involved in the recruitment of uninfected cells. HIV-1 viral proteins can upregulate the expression of inflammatory cytokines and adhesion molecules in endothelial cells thereby facilitating the entry of immunocompetent cells into the brain. Our results show that heroin up regulates both ICAM-1 and VCAM-1 ny BMEC that may exacerbate extravasation of HIV-1 infected cells.

Heroin crosses the BBB in the CNS and converts to morphine which binds rapidly to opioid receptors. Studies have shown up regulation of mu opioid receptor expression in neural microvascular endothelial cells and provide evidence of a relationship between opioids and cytokines suggesting that opioid-dependent pathways may be modulated in HIV-1 AIDS dementia ${ }^{[19,36]}$. Drugs of abuse act as co-factors in the neuropathogenesis of HIV-1 by facilitating BBB dysfunction. Several previous studies including our own ${ }^{[17-19,37]}$ suggest that opiates alone and in combination with HIV-1 viral proteins exacerbate the neuropathogenesis of HIV-1. Heroin has a stimulatory effect on the release of IL-1 $\beta$, IL-2, TNF- $\alpha$ and IFN- $\gamma \square$ which may induce NO production via the modulation of iNOS gene expression ${ }^{[38]}$. We suggest that the increased NO production results in an upregulation of adhesion molecules which facilitates the rolling and binding of transmigrating immunocompetent cells thereby modulating $\mathrm{BBB}$ permeability and facilitating viral entry in to the CNS. HIV-1 viral proteins also induce the production TNF- $\alpha$ and IL1 $\beta$, both of which are implicated in producing neurotoxicity and in the pathogenesis of HIV-1 encephalopathy, additionally they can stimulate the CNS cells to produce inducible form of nitric oxide synthase (iNOS) and induce the expression of adhesion molecules on glial cells and produce cytoskeletal changes ${ }^{[3,39]}$. Our results show that heroin treatment significantly increases both the genotypic and phenotypic expression of ICAM-1, VCAM-1 and iNOS in BMVEC. These data confirm the role of opiates like heroin and morphine in the neuropathogenesis of HIV-1 and also provide a direct evidence for its role in BBB dysfunction.

\section{ACKNOWLEDGEMENTS}

This work was supported in part by NIDA grants RO1-DA14218, RO1-DA10632, RO1-DA12366, RO1DA15628, 1RO1DA02153701, 1F32DA02153501 and the Margaret Duffy and Robert Cameron Troup Memorial Fund of Kaleida Health, Buffalo, NY.

\section{REFERENCES}

1. Hawkins, B.T. and T.P. Davis, 2005. The bloodbrain barrier/neurovascular unit in health and disease. Pharmacol. Rev., 57: 173-185.

2. Kanmogne, G.D., R.C. Kennedy and P. Grammas, 2002. HIV-1 gp120 proteins and gp160 peptides are toxic to brain endothelial cells and neurons: possible pathway for HIV entry into the brain and HIV-associated dementia. J. Neuropathol. Exp. Neurol., 61: 992-1000.

3. Nath, A. and J.D. Geiger, 1998. Neurobiological aspects of HIV infections: neurotoxic mechanisms. Prog. Neurobiol., 54: 19-33.

4. Nath, A., 2002. Human immunodeficiency virus (HIV) proteins in neuropathogenesis of HIV dementia. J. Infect. Dis., 186: S193-S198.

5. Kolson, D.L., 2002. Neuropathogenesis of central nervous system HIV-1 infection. Clin. Lab. Med., 22: 703-717. 
6. Kolson, D.L., E. Lavi and F. Gonzalez-Scarano, 1998. The effects of human immunodeficiency virus in the central nervous system. Adv. Virus Res., 50: 1-47.

7. Kolson, D.L. and F. González-Scarano, 2000. HIV and HIV dementia. J. Clin. Invest., 106: 11-13.

8. Kim, T.A., H.K. Avraham, Y.H. Koh, S. Jiang, I.W. Park and S. Avraham, 2003. HIV-1 TatMediated Apoptosis in Human Brain Microvascular Endothelial Cells J. Immunol., 170: 2629-2637.

9. Nottet, H.S., Y. Persidsky, V.G. Sasseville, A.N. Nukuna, P. Bock, Q.H. Zhai, L.R. Sharer, R.D. McComb, S. Swindells, C. Soderland and H.E. Gendelman, 1996. Mechanisms for the transendothelial migration of HIV-1-infected monocytes into brain. J. Immunol., 156: 12841295.

10. Nottet, H.S, 1999. Interactions between macrophages and brain microvascular endothelial cells: role in pathogenesis of HIV-1 infection and blood - brain barrier function. J. Neurovirol., 5: 659-669.

11. Persidsky, Y., J. Zheng, D. Miller and H.E. Gendelman. 2000. Mononuclear phagocyte mediate blood-brain barrier compromise and neuronal injury during HIV-1-associated dementia. J. Leukoc. Biol., 68: 413-422.

12. El-Hage, N., J.A. Gurwell, I.N. Singh, P.E. Knapp, A. Nath and K.F. Hauser, 2005. Synergistic increases in intracellular $\mathrm{Ca} 2+$ and the release of MCP-1, RANTES and IL-6 by astrocytes treated with opiates and HIV-1 Tat. Glia., 50: 91-106.

13. Rothlein, R., M. L., Dustin, S. D. Marlinand T. A. Springer, 1986. A human intercellular adhesion molecule (ICAM-1) distinct from LFA-1. J. Immunol., 137: 1270-1274.

14. Van de Stolpe, A. and P.T. van der Saag, 1996. Intercellular adhesion molecule-1. J. Mol. Med., 74: 13-33.

15. Yu, X., X. Mao, A.D. Blake, W.X. Li and S.L. Chang, 2003. Morphine and endomorphins differentially regulate micro-opioid receptor mRNA in SHSY-5Y human neuroblastoma cells. J. Pharmacol. Exp. Ther., 306: 447-454.

16. Wang, X., N. Tan, S.D. Douglas, T. Zhang, Y.J. Wang and W.Z. Ho, 2005. Morphine inhibits CD8+ $\mathrm{T}$ cell-mediated, noncytolytic, anti-HIV activity in latently infected immune cells. J. Leukoc. Biol., 78: 772-776.

17. Mahajan, S.D., S.A. Schwartz, T.C. Shanahan, R.P. Chawda and M.P. Nair, 2002. Morphine regulates gene expression of alpha- and beta-chemokines and their receptors on astroglial cells via the opioid mu receptor. J. Immunol., 169: 3589-3599.
18. Mahajan, S.D., R. Aalinkeel, J.L. Reynolds, B.B. Nair, S.F. Fernandez, S.A. Schwartz and M.P. Nair, 2005. Morphine exacerbates HIV-1 viral protein gp120 induced modulation of chemokine gene expression in U373 astrocytoma cells. Curr. HIV Res., 3: 277-288.

19. Chang, S.L., B.M. Sharp and J.J. Madden, 1998. Cellular mechanisms involved in the modulation of the immune system by drugs of abuse. Adv. Exp. Med. Biol., 437: 1-12.

20. Nair, M.P.N., R. Pottathil, E.P. Heimer and S.A. Schwartz, 1988. Effect of HIV recombinant and synthetic peptides on human immunodeficiency virus proteins. I. Effect of HIV recombinant and synthetic peptides on immunoglobulin synthesis and proliferative responses by normal lymphocytes. Proc. Natl. Acad. Sci. USA, 85: 6498-6502.

21. Nair, M.P.N., S. Mahajan and S.A. Schwartz, 2000. Immunomodulatory roles of heroin and HIV protein on nitric oxide production by brain microvascular endothelial cells. NIDA Res. Mono., 181: 85-86.

22. Damico, R.L., J. Crane and P. Bates, 1998. Receptor-triggered membrane association of a model retroviral glycoprotein. Proc. Natl. Acad. Sci. USA, 95: 2580-2585.

23. Bianchi, G., G. D'Amico, L. Varone, S. Sozzani, A. Mantovani and P. Allavena, 2000. In vitro studies on the trafficking of dendritic cells through endothelial cells and extra-cellular matrix. Dev. Immunol., 7: 143-53.

24. Chomczynski, P and N. Saachi, 1987. Single step method of RNA isolation by acid guanidinium thiocyanate-phenol-chloroform extraction. Anal. Biochem., 162: 156-159.

25. Shively L., L. Chang, J. M. LeBon, Q. Liu, A. D. Riggs, J. Singer-Sam, 2003 Real-time PCR assay for quantitative mismatch detection. Biotechniques, 34: 498-502, 504.

26. Osborn, L., C. Hession, R. Tizard, C. Vassallo, S. Luhowskyj, G. Chi Rosso and R. Lobb, 1989. Direct expression cloning of vascular cell adhesion molecule 1, a cytokine-induced endothelial protein that binds to lymphocytes. Cell, 59: 1203-1211.

27. Graver, N., T. Venkat Gopal, D. Wilson, D. Beall, T. Polte, W. Newman, 1990. T cells bind to cytokine-activated endothelial cells via a novel, inducible sialoglycoprotein and endothelial leukocyte adhesion molecule-1. J. Immunol., 145: 819-830.

28. Moses, A.V., F.E. Bloom, C.D. Pauza and J.A. Nelson, 1993. Human immunodeficiency virus infection of human brain capillary endothelial cells occurs via a CD4/galactosylceramide-independent mechanism. Proc. Natl. Acad. Sci. USA, 90: 10474-10478. 
29. Radisavljevic, Z., H. Avraham and S. Avraham, 2000. Vascular endothelial growth factor upregulates ICAM-1 expression via the phosphatidylinositol $3 \mathrm{OH}$-kinase/AKT/nitric oxide pathway and modulates migration of brain microvascular endothelial cells. J. Biol. Chem., 275: 20770-20774.

30. Welters, I.D., C. Fimiani, T.V. Bilfinger, G.B. Stefano, 2000. NF-kappaB, nitric oxide and opiate signaling. Med. Hypotheses, 54: 263-268.

31. Boje, K.M. and S.S. Lakhman, 2000. Nitric oxide redox species exert differential permeability effects on the blood-brain barrier. J. Pharmacol. Exp. Ther., 293: 545-550.

32. Langford, D. and E. Masliah, 2001. Crosstalk between components of the blood brain barrier and cells of the CNS in microglial activation in AIDS. Brain Pathol., 11: 306-12.

33. Schmidtmayerova, H., H.S. Nottet, G. Nuovo, T. Raabe, C.R. Flanagan, L. Dubrovsky, H.E. Gendelman, A. Cerami, M. Bukrinsky and B. Sherry, 1996. Human immunodeficiency virus type 1 infection alters chemokine beta peptide expression in human monocytes: implications for recruitment of leukocytes into brain and lymph nodes. Proc. Natl. Acad. Sci. USA, 93: 700-704.
34. Bobardt, M.D., P. Salmon, L. Wang, J.D. Esko, D. Gabuzda, M. Fiala, D. Trono, B. Van der Schueren, G. David and P.A. Gallay, 2004. Contribution of proteoglycans to human immunodeficiency virus type 1 brain invasion. J. Virol. 78: 6567-6584.

35. Woodman, S.E., E.N. Benveniste, A. Nath and J.W. Berman, 1999. Human immunodeficiency virus type 1 TAT protein induces adhesion molecule expression in astrocytes. J. Neurovirol., 5: 678-684.

36. Vidal, E.L., N.A. Patel, G. Wu, M. Fiala and S.L. Chang, 1998. Interleukin-1 induces the expression of $\mathrm{mu}$ opioid receptors in endothelial cells. Immunopharmacology, 38: 261-266.

37. Nath, A., K. Conant, P. Chen, C. Scott, E.O. Major, 1999. Transient exposure to HIV-1 Tat protein results in cytokine production in macrophages and astrocytes. A hit and run phenomenon. J. Biol. Chem., 274: 17098-102.

38. Hauser, K.F., N. El-Hage, S. Buch, J.R. Berger, W.R. Tyor, A. Nath, A.J. Bruce-Keller and P.E. Knapp, 2005. Molecular targets of opiate drug abuse in neuroAIDS. Neurotox. Res., 8: 63-80.

39. Price, T.O., N. Ercal, R. Nakaoke and W.A. Banks, 2005. HIV-1 viral proteins gp120 and Tat induce oxidative stress in brain endothelial cells. Brain Res., 1045: 57-63. 